\title{
Health Workers' Educational Training and Staffing Concerning Medication Errors, Fall Injuries, and Complaints among Older Adults
}

\author{
Zafar Mehdi ${ }^{1}$, Ramzi Nasser ${ }^{2}$, Hildegard Theobald ${ }^{3} \&$ Klaus Schoemann ${ }^{4}$ \\ ${ }^{1}$ Dhofar University, Salalah, Oman \\ ${ }^{2}$ University of Sharjah, Sharjah, United Arab Emirates \\ ${ }^{3}$ University of Vechta, Vechta, Germany \\ ${ }^{4}$ Jacobs University, Bremen, Germany \\ Correspondence: Ramzi Nasser, College of Arts, Humanities and Social Science, University of Sharjah, \\ University City, Sharjah, UAE. Tel: 971-65-053-338. E-mail: rnasser@sharjah.ac.ae
}

\author{
Received: January 10, 2019 Accepted: February 17, 2019 Online Published: February 25, 2019 \\ doi:10.5539/gjhs.v11n3p111 URL: https://doi.org/10.5539/gjhs.v11n3p111
}

\begin{abstract}
Several mandatory and voluntary further training programs in healthcare and long-term care sectors are available in Canada. However, the relation between further training of care workers and quality of patient care in hospitals, home care settings, and residential care facilities are unclear. This study investigates the association of further training of nurses, healthcare workers, and care assistants, as well as the health workers' staffing levels with quality of life of older adults in Canada. Cross-sectional data, which included quality of life variables, such as medication errors, fall injuries, and complaints of older adults across healthcare and social care sectors, were drawn from the Canadian National Survey of the Work and Health of Nurses. The additional training of health workers has a positive association with quality of elder care by reducing incidence of fall injury and medication error and increasing resident satisfaction of patients. Staffing level among health workers is also positively associated with these quality of life variables. The findings of the study suggest that health worker staffing level and further professional training can improve quality of life of older adults. This study is original in that it examined a national representative sample from Canada and quality of life variables. Previous studies have not used such a survey thus far. Moreover, this study is unique because it connects professional development and further education to quality of life factors, such as incidence of fall injuries and medication errors, and resident satisfaction.
\end{abstract}

Keywords: health workers, medication errors, fall injury, staffing level, older adults, further education, professional development

\section{Introduction}

Canada continues to tackle an aging population in which the proportion of older people to the total population is expected to increase by $23 \%$ and $25 \%$ higher in 2036 , thereby affecting the healthcare system. As older people live longer, their healthcare and long-term needs, also increase. Moreover, because of the growth of nuclear family, not only Canada but also worldwide, fewer older people are able to stay in their homes or with family members, thereby intensifying their reliance on health workers in elder homes. The greater the personal care and assistance for those who are in need of home support, the greater the ability for them to function normally in daily activities (C. D. Howe Institute, 2013).

Older adults experiencing health problems are dependent on family and health services and in need of some or complete assistance related to their activities of daily living. Policymakers, governments, and health institutions work to ensure care service in different settings, such as hospitals, long-term residential care facilities, and home care. All older adults must receive proper care and workers must update their knowledge and skills in the area of elder care (Mehdi, 2015).

According to the Canadian Nurses Association, health workers are accountable for direct or indirect care services for healthcare patients in hospitals, long-term residential care facilities, and home care settings. Therefore, professional development is an essential component of healthcare workers' knowledge and understanding of the needs of older adults. Health workers must be up-to-date with the new knowledge, whether theoretical or practical, so that they may apply it to their workplace and the area of elder care (Mehdi, 2015). Professional training and 
advanced knowledge practices lead to advancement in career opportunities for health workers. The nursing literature suggests that professional education improves quality of nursing healthcare and effectiveness of patient care (Fumic, Marinovic, \& Brajan, 2014). However, health workers are unable to participate in professional development programs outside their workplace because of busy schedules (Muliira \& Muliira, 2012), and to pay for training on their own as they are among the lowest paid employees in the white-collar professions (Stone \& Weiner, 2001). Although many educational programs for health workers have been initiated by long-term care facilities, the effectiveness of additional training remains unclear (Aylward et al., 2003).

Many studies have been conducted on training approaches and content among healthcare professions, but studies on the impact of such programs on quality of care are scarce (Stiggelbout et al., 2012). There are also few studies on the effectiveness of continuing education of registered nurses (RNs) and staffing level on nursing practice and quality of patient care in hospitals (Aiken et al., 2011). A study on bedside care workforce showed that a greater proportion of highly skilled professional nurses is associated with better health-related outcomes for patients (Aiken et al., 2013). Studies have also increasingly suggested that significant investment in further professional education and training could enhance health workers' knowledge and skills to meet the needs of patients effectively. However, there is limited evidence on the association of further professional education with care practice (Clark, Draper, \& Rogers, 2015). The premises of this study suggest that quality care is situated in the context of care and physical and psychological health. Key factors as injury, medication error and elderly satisfaction are studied in relation to training and staffing level.

\subsection{Fall Injury}

Many residents in nursing homes have not received appropriate medical and nursing care showing that nursing in residential homes are of low quality compared with that in hospitals (Millard, 1989; 13, Craig, 1995). Older adults are more susceptible to accidents, such as falls and have little control over daily life activities. Injury by fall accounts for $90 \%$ of hip fractures due to impact from the fall or poor bone strength (Woolf \& Akesson, 2003). Most older adults have poor nutrition, which is contrary to the necessity of maintaining a healthy diet to increase bone strength and reduce trauma due to injury (Woolf \& Akesson, 2003). In fact, older adults who take vitamins on a regular basis experience substantial changes in their lifestyles. Therefore, the healthcare of older adults must be in accordance with health and safety standards; on this subject, many issues are raised concerning health workers' expertise and advanced knowledge. Health workers must follow specific patient and staff educational programs to raise awareness of accident prevention (Mwanri \& Fuller, 2003) and learn about pre-emptive means that protect older adults.

\subsection{Medication Error}

The common theme in the literature on polypharmacy suggests that intensified adverse drug reactions and non-adherence to medical treatment could result in adverse health risks (Cleary \& Howell, 2007). All groups of older adults are likely to increase their dependence on medication as they age, that is, taking a regimen of drugs three to four times a day. However, few older adults can keep up with the medication schedule independently; non-adherence may increase morbidity and mortality incidence (Urquhart, 1994). Empirical evidence indicates that medication error accounts for about more than 7,000 deaths annually (Institute of Medicine, 1999), making it an important measure of quality of care. In nursing research, low staffing level is among the reasons medication errors occur, which may result in erroneous administration of medication in hospitals or long-term care settings.

Considerably, several concurrent drugs have resulted in a high number of chronic conditions and are positively associated with poor adherence (Billups, Malone, \& Carter, 2000). As the number of administered medicines increases, the probability of error and mistakes increases as well. Chan, Nicklason, and Vial (2001) found that 26\% of hospital admissions were a result of medication non-adherence and the omission and cessation of a medication regimen. Grocki and Huffman (2007) suggested that health workers have a responsibility and ethical obligation, whether intentional or unintentional, to improve the lives of older adults.

Medication errors are compounded with the mistakes of older adults in their ability to regularly keep up with their medication. They may be unable to recollect exactly when and what drugs they have taken or the regimen and schedule they maintain. Health workers in elder homes bear the greater responsibility to monitor and administer drug dosages; as such, they are responsible for the drug treatment of older adults (Berthenet, Vaillancourt, \& Pouliot, 2016).

Other types of medication errors may result from polypharmacy mismanagement in long-term care homes. For instance, elder residents undergo a complicated medication regimen, and any change in their regular drug dosages leads to adverse effects on their health. Health workers must be aware of the medication schedule, medication 
history, administration schedules, and dosages of drugs. When health workers' shifts change, they may make mistakes or get confused about dosage levels and administration. Additionally, the unethical and/or dishonest acquisition of drugs by health workers for personal use and their professional misconduct (Chambers \& FRCCP, 1999) can lead to intentional misadministration of drugs.

\subsection{Complaints (Resident Satisfaction)}

Because elder care is becoming more complex, the knowledge and skills of nurses must be up-to-date so that they can support and improve the quality of life. We argue that satisfaction with life of older people in an elder home setting depends on the social and medical care they obtain. However, other life trajectories, such as social participation, family, community, and social support (Walker, 2005; Wilhelmson, Andersson, Waern, \& Alleberck, 2005; Zaninotto, Falaschetti, \& Sacker, 2009; Burton-Jeangros \& Zimmermann-Sloutskis, 2016), may also impact their life quality. Although family and friends provide security and recognition within their family homes (Hayat, Khan, \& Sadia, 2016), older adults in elder homes might feel completely isolated from their environments. In elder homes, which may deteriorate their quality of life substantially. Thus, the role of health workers is significant in providing comfort and support and in alleviating the satisfaction of older adults' quality of life. We also argue that satisfaction with care service enables them to perceive better quality of life. Thus, this study examined three important factors: injury, medication error, and resident satisfaction. Evidence suggests a strong association between quality of care and quality of life mediated by health satisfaction (Hsieh, 2009). Certainly, older adults need social support whether living inside or outside an elder home. In elder homes, health workers are the main actors that provide support for older adults, by ensuring that residents experience a certain level of comfort, including social support and material, safety, and health needs (Borg, Hallbergir, \& Blomqvist, 2006, 2014). McCartan-Quinn et al. (1996) revealed that older adults have low level of satisfaction with the level of information and social needs they receive in elder homes. The support they receive is associated directly with the older adults' sickness, demographic factors, and clinical features. However, according to Chiaelli and Beradi (2011), the pattern of intervention, whether in a physician follow-up or health workers, seems to influence older adults' assessment of medical care and social support. Moreover, older adults perceive that positive health is correlated with greater life satisfaction (Mollaoglu, Tuncay, \& Fertelli, 2010); it is more likely, those with poor health condition perceive low life satisfaction. Forbes (2001) suggested that health workers is the best predictor of satisfaction in the Canadian healthcare system, as they work consistently and uniquely with older adults and usually take care of the same residents (Forbes, 2001). In this regard, health workers are supposed to assist older adults in terms of providing professional medical care and social support.

\subsection{Staffing Level}

Aiken et al. $(2003,2011)$ discovered that staffing level is associated with quality of care. However, the impact of an educational composition of RNs and elder care workers remains unclear. Research on staffing, patient outcomes, and injuries in older adults has been inconsistent. Although several studies have found no association between levels of staffing and adverse health conditions (Silber \& Rosenbaum, 1997), others have reported that increased levels of staffing are associated with a lower mortality rate among older adults (Hartz et al., 1989). These contradictory results may be explained by the inability of hospitals to assess the association of staffing levels with outcomes of injury and medication errors among older adults (Needleman et al., 2002). In fact, controlling for such outcomes is difficult as they can occur outside the hospital or at homes where data are not easily obtainable. Thus, this study examines the association of staffing levels with medication errors, injury and satisfaction levels among older adults residing in nursing homes.

\subsection{Nursing Training in Canada}

Potential health workers take science subjects, such as chemistry, physics, and biology, in the last two years of secondary school to get into nursing programs or schools at professional colleges or universities (Health Force Ontario Canada, 2015). Until 1995, to become an RN, a three-year diploma in nursing programs at a professional college affiliated with a hospital was required. However, after 1995, this requirement was changed, and all provinces in Canada were encouraged to start a four-year bachelor's degree in nursing science (Canadian Nurses Association, 2015). Currently, in all 10 provinces and three territories, except Quebec, a four-year bachelor's degree in nursing is required to become an RN. Other than RNs, licensed practical nurses (LPNs) and registered psychiatric nurses (RPNs) are required to receive a nursing license. LPNs are required by law to have a similar nursing education as an RN, but a shorter training duration of two years (or a two-year diploma). RPNs need to complete a three-year diploma or a four-year bachelor's degree in mental health (Canadian Nurses Association, 2015). Some provinces prefer a bachelor's degree in mental health, whereas others still accept a three-year diploma for practice. However, a four-year degree is preferred throughout Canada. 


\subsection{Further Training of Elder Carers and Care Assistants}

In Canada, further training for RNs and RPNs requiring specialty courses leads to higher education qualifications. Nurses with a bachelor's degree can undergo additional training to achieve a master's or doctoral degree in nursing (Canadian Nurses Association 2015). Nursing care assistants who work in long-term care facilities, residential care facilities, and home care settings, receive professional training under the direction of nurses and elder carers. They need up to one year of training for a recognizable qualification. For unskilled or low skilled care assistants/workers, on-the-job care training is provided. To obtain a certificate, a training lasting between 6 and 12 months is required (Canadian Nurses Association \& Registered Nurses' Association of Ontario, 2010). In different provinces or professional colleges, various names or labels, such as care aide, senior caregivers for older adults, and personal and home support workers, are given for elder carers.

\subsection{Objectives and Research Questions}

This study used two main independent variables, namely, staffing level and further education, and three dependent variables, namely, medication errors, fall injuries, and complaints of residents, which served as a proxy measure of satisfaction. The first research question was on the association of staffing level with medication errors, fall injuries, and complaints of older adults. The second question was on the association of training (i.e., post certification) with medication errors, fall injuries, and complaints of older adults.

The main framework and theory of quality care suggest that an effective training has a greater impact on quality of life of older adults. Lifelong learning for healthcare workers who work in home care locations, hospitals, or long-term residential care settings is indispensable for professional development and care skills for safe patient care. Continuing learning of nurses through their career enriches their knowledge and skills and keeps them up-to-date with the changes in technology and healthcare environment over time.

\section{Method}

\subsection{Data}

In this study, data were drawn from the Canadian National Survey of Work and Health of Nurses (NSWHN, 2005). The selected variables were never repeated in other Canadian surveys. The sample was selected systematically. A total of 18,676 RNs, LPNs, and RPNs, who were employed in various healthcare settings in all provinces and territories of Canada were interviewed. Nurses working in hospitals, long-term care facilities, and home care settings were included in this survey. Nurses answered questions on quality of patient care, including medication errors, fall injuries, and residents' complaints.

\subsection{Measures}

The dependent variables were measured through perceptions of health workers on issues pertaining to adverse events or occurrences among patients such as medication errors, falls and satisfaction. Because resident satisfaction is a broad and multidimensional measure, we used number of complaints as a proxy measure, where a lower number of complaints means a higher level of satisfaction, and vice versa. The independent variables as staffing level measurement was based on their perception during their shift, ratio between number of patients and number of nurses on duty during their shifts at their work setting, such as hospital, long-term care facility, community health setting and others settings (Physicians officer, private nursing agencies, educational institutions and government associations). Training was measured through years training post degree certification; the unit of measurement was in years.

\subsection{Research Design}

We ran three different overarching regressions using two independent variables, that is, staffing level and further training. The dependent variables were medication errors, fall injuries, and complaints of older adults. A regression determined the association of further training with income, then three overarching regressions defined the predictive power of post-basic education and staffing levels on three important elder conditions.

A precursor analysis using annual and employment earnings as dependent variables were regressed by the independent variables of age, post-basic training, and experience. As the years of education increase, the probability of earnings also rises. To investigate how further training affects nurses' and elder carers' annual earnings, a regression analysis was performed. 


\section{Results}

Table 1. Demographic characteristics of health care workers in Canada

\begin{tabular}{llll}
\hline Characteristics & Nurses \% & Elder Carers \% & Care Assistant \% \\
\hline Age & 54.6 & 45.2 & 56.6 \\
$\leq 45$ years & 45.4 & 55.8 & 43.4 \\
$>45$ years & 100 & 100 & 100 \\
Total & & & \\
\hline Gender & 16.6 & 2.8 & 13.4 \\
Male & 83.4 & 97.2 & 86.6 \\
Female & 100 & 100 & 100 \\
Total & & & \\
\hline Nursing Training & 56.0 & 92.3 & 87.2 \\
Basic-level & 44.0 & 7.7 & 12.8 \\
Post-basic level & 100 & 100 & 100 \\
Total & 100 & & 100 \\
\hline Employment Status & 0 & 100 & 0 \\
Employed & 100 & 0 & 100 \\
Unemployed & 100 & 7.4 \\
Total & 10.5 & 26.0 & 92.6 \\
\hline Wages/Salary/month & 89.5 & 74.0 & 100 \\
$\leq 3480$ Dollars & 100 & 100 & \\
$\geq 3500$ Dollar & & & \\
Total & & 100 & \\
\hline Solnc: SLD $2010(C a n$ & & & \\
\hline
\end{tabular}

Source: SLID 2010 (Canada) datasets.

\subsection{Employment, Income, and Earnings}

Table 1 presents data on demographic factors and participants' income and earnings. During the Labour and Income Dynamics (SLID) survey, all nurses, elder carers, and care assistants were employed either full time or part-time throughout the year; none was unemployed. Therefore, unemployment statistics among healthcare workers are not available in this study. Additionally, the average monthly salary of RNs (with a bachelor's degree) was between Canadian Dollars 5,000 and Canadian Dollars 6,000 (EUR 3,600) (Living in Canada, 2015). In 2010, $90 \%$ of Canadian RNs had an equivalent amount of salary. Monthly salary depends on the national or provincial minimum wage per hour. In Canada, healthcare workers' (caregivers) hourly wage on average is between Canadian Dollars 9.98 and Canadian Dollars 19.35, with an annual bonus of up to Canadian Dollars 1,021 (National Pay Scale, 2015). 
Table 2. Average monthly wages and Annual labour earnings by age, gender and further training in Canada

\begin{tabular}{|c|c|c|c|c|}
\hline & \multicolumn{2}{|l|}{ Nurses } & \multicolumn{2}{|c|}{ Elder Carers } \\
\hline & P-Value & Odds Ratio & P-Value & Odds Ratio \\
\hline \multicolumn{5}{|l|}{ Dependent Variable } \\
\hline \multicolumn{5}{|l|}{ Annual Labour Earning } \\
\hline \multicolumn{5}{|l|}{ Independent Variables } \\
\hline Age & 0.485 & 0.941 & 0.468 & 0.899 \\
\hline Post-basic training (in years) & 0.006 & 1.536 & 0.000 & 1.850 \\
\hline Experience (in years) & 0.767 & 1.118 & 0.000 & 1.862 \\
\hline
\end{tabular}

Source: Computed from SLID 2010 data, * Elder carers include care assistants.

Table 2 presents the results of the regression analysis using income as the dependent variable and age, post-basic training, and experience as the independent variables. Although Canadian healthcare workers' further training had no positive association with annual earnings, the 10 or more years of experience of nurses were associated with annual earnings. The same number of years of experience of elder carers and care assistants were positively associated with their annual earnings. These findings suggest that the further training of low skilled workers was not correlated with their annual earnings but had a moderate correlation with number of years of experience and annual earnings, including overtime and annual bonuses.

\subsection{Fall Injury}

Table 3 presents the main regression results. The analysis showed that staffing level and post-basic education had a positive association with the prevention of fall. Adequate staffing and additional nursing staff have a positive impact on prevention of fall. The findings from this study showed that healthcare facilities with adequate staff was 1.311 times more likely to prevent a resident's fall injury.

\subsection{Medication/Dose Errors}

The second analysis investigated the association of nursing education with medication errors. The findings of the logistic regression indicated a positive association of advanced training (higher degrees) of nurses with rare medication errors (Table 2). The odds ratio indicated that nurses with advanced training or a higher level of nursing training are 1.015 times less likely to give wrong medication to residents when compared with those with a lower level of nursing training. Adequate staffing level is also positively associated with rare medication errors. Healthcare settings with adequate staff have a 1.045 times higher probability of rare medication errors.

Table 3. Wrong medication/dose, complaints from patients, and Injury by advanced education and staffing level

\begin{tabular}{lll}
\hline Independent variables & P-Value & Odds Ratio \\
\hline Injury in a fall & & 1.311 \\
Staffing level & 0.000 & 1.052 \\
Post-Basic Education & 0.000 & \\
\hline Medication Error & & 1.045 \\
Staffing level & 0.000 & 1.015 \\
Post-Basic Education & 0.000 & \\
\hline Complaints from Patients & & 1.240 \\
Staffing level & 0.000 & 0.858 \\
Post-Basic Education & 0.000 & \\
\hline
\end{tabular}

\subsection{Complaints From Residents}

Shortage in nursing staff in busy care settings may lead to complaints from residents; accordingly, adequate staffing helps reduce the number of residents' complaints. The results showed that complaints were minimized by 
1.240 times when there was adequate staff. Regarding nursing education, data showed a negative relationship between advanced nursing education and complaints. The odds ratio $(0.858)$ implied that nurses with advanced education were more likely to have complaint than those with a lower educational level. This finding suggests that nurses with advanced education take on several roles and responsibilities, such as administrative tasks, and thus are more likely to work with doctors, give instructions to lower-ranked staff, and oversee the whole ward and thus do not have much time to spend with all residents and their families.

\section{Discussion}

Elder carers and care assistants undergo training in different areas of nursing. They have less time or fewer opportunities to upgrade their qualification upon completion of their education or when working. Those who have a strong commitment to enhance their knowledge and skills can be admitted to off-the-job training programs according to their educational level and interest in a specific area of nursing. This study proposed that further training of nurses in Canada enables them to enhance their knowledge and skills. This study also found that a 10 -year working experience did not increase the earnings of nurses but it did for health workers and nurse assistants. Therefore, this study suggests that an increase in earning that is commensurate with a nurse's advanced training could encourage health workers to seek further education and professional development in the profession.

RNs in Canada have opportunities to further their training towards higher educational qualifications, especially those who already have a bachelor's degree. Their basic level of education would allow them to move forward and be able to receive additional training towards a master and doctoral degrees in nursing for their career advancement, whether in teaching, research, or management positions. This study addressed the staffing levels in relation to incidence of fall injuries and medication errors. The difficulty of analysing those factors as injuries and medication error is that it is not easily established or validated because they happen post-hospital discharge outside an elder home setting. Nevertheless, assessing care for older adults in relation to quality of life is easier among those living in elder homes under a long-term care because they have a much more controlled environment.

The results of the study indicated that further professional development and training had a positive association with preventing medication errors. Although many studies have indicated that medication errors lead to cases of morbidity and even death (Urquhart, 1994), providing on-time and correct medication improves the overall quality of care and are important elements in maintaining the health and knowledge of polypharmacy drugs use among older adults. With increased staffing, there was a lesser probability of medication errors. This strong association indicated that with an appropriate staffing level, health workers can meet the required levels of care and may provide organizational directives. Moreover, although this study did not consider the combination of staffing levels and medication errors, it statistically addressed the unique variations of training and staffing levels. We believe that a sufficient number of trained health workers will provide quality care to older adults. Most elder carers in Canada surveyed had the qualification and work experience but were less likely to have undergone an advanced training. On-site professional development programs without the disruption of the work regimen of healthcare workers and care for older adults would encourage health workers to commit themselves and open the trajectory for career advancement. The increase in care needs and shortage of skilled nursing staff has become a compelling healthcare issue in home care sector in Canada. To address this issue, it may be beneficial to recruit skilled healthcare workers or provide further training to low skilled healthcare workers to meet home care demands.

The second finding of this study suggested that the higher the training, the lower the probability of injuries. Certainly, the literature on older adults showed that environmental factors are significant to the safety of older adults (Cesari et al., 2002). Healthcare workers may take precaution in the way they provide greater care for older people, protecting the frail body from injury by dressing them properly and designing a safe environment. The recorded level of staffing is more significant; the greater the number of staff members, the less likely older adults would fall. Therefore, proper staffing and training will most likely allow for pre-emptive measures to protect the latter from harm.

The final results of this study were related to satisfaction. Because the national data had no direct valid and reliable measures of satisfaction, this study used the number of complaints of older adults as a proxy measure to satisfaction. Although complaints may include those regarding the environment and ability to move freely in elder home settings, there was a probability that a lower number of complaints (satisfaction) would be associated with how health workers cared for the older adults. This study found that health workers with an advanced level of education would have 0.858 times more probability to have a higher number of complaints. A robust generalization suggests that satisfaction with the service is strongly associated with further training of health workers. This finding differs based on healthcare environment. The most important influence in older adults' satisfaction is accessibility to the desired space (environment) and a health worker's continuity, humaneness, and 
thoroughness of care (Donabedian, 1966; Feletti, Firman, \& Sanson-Fisher, 1986).

Older adults have emotional attachment to their homes and spend most of their adult lives in their homes. Any sort of change to the ecosystem will lead to an adverse experience and deterioration of the level of their physical ability and thus can result in a lack of independence. These conditions may also cause the disintegration and restriction of living space activities and, in extreme circumstances, a process of early institutionalization (Perez et al., 2001). To compensate, health workers plays a role especially in supporting older adults to adjust to their new living environment ( $\mathrm{Lu} \&$ Chang, 1997). The results of this clearly indicated in that to enhance quality of life, health workers' role is important in improving the lives of older adults. Therefore, improving their work through either attending trainings within or outside the institution in which they work or completing an advanced education is necessary.

\section{Conclusion, Recommendations, and Implications for Practice}

This study is original but it is limited by a set of variables that could act uniquely (namely, training and staff levels) or in unison in impacting older adults' well-being. Certainly, there is a need to expand on those aspects at a global level, particularly in countries with ageing population. However, in Canada, to support such an approach is less likely to happen. A national health strategy should adopt an aggressive stance to recruit, sustain, and continuously train health workers. The health system shall also address the shortage of health workers and increase targets for professional development and sustenance. Currently, Canada relies on immigrant health workers. With immigration laws becoming tighter (Stewart et al., 2006), the need to provide further education and recruitment of health workers in Canada is quite immense.

\subsection{Implication for Practice}

The data in this study suggested that further training of health workers at nursing schools and universities require teachers and researchers to address the adverse events in hospitals, nursing homes, and home care settings, and discuss the strategies to prevent these safety risks for patients. The risk of medication errors and fall injuries is higher among older adults. Medication errors and fall injuries also have the potential to increase healthcare costs as they may lead to longer stay at hospitals and medical complications. Cases of medication errors, fall injuries, and complaints may be reduced by increasing the number of nursing staff and providing further training on adverse events. Further training and advanced knowledge on these issues enhance health workers' competency and prevent these adverse events. To prevent medication errors, nurses should ensure that they have minimal distractions because being distracted is a primary cause of error. If a nurse is not sure about the medication dose, an elder carer is obliged to ask the physicians who prescribe it or his/her senior co-workers. Health workers can take numerous preventive actions to reduce the likelihood of adverse events.

These adverse events at hospitals and nursing homes can influence public attitude about the standard of healthcare quality and the institutions. The reports on these adverse events might have a negative impact on the reliability and efficiency of healthcare settings. These events are also likely to have social and commercial consequences. Proper nurse staffing strengthens the healthcare system and improves patient safety. Although there is shortage of healthcare workers in Canada, the Canadian Institute for Health (2018) reported that in Canada, there are 1,102 nurses (RNs and other nursing practitioners) per 100,000 people or about one nurse per 100 people. This study suggests that nurse leaders and employers must address staffing needs and employ nurses appropriately in every healthcare environment.

\section{Competing Interests Statement}

The authors declare that there are no competing or potential conflicts of interest.

\section{References}

Aiken, L. H., Cimiotti, J. P., Sloane, D. M., Smith, H. L., Flynn, L., \& Neff, D. F. (2011). The effects of nurse staffing and nurse education on patient deaths in hospitals with different nurse work environments. Medical Care, 49(12), 104. https://doi.org/ 10.1097/MLR.0b013e3182330b6e

Aiken, L. H., Clarke, S. P., Cheung, R. B., Sloane, D. M., \& Silber, J. H. (2003). Educational levels of nurses and surgical patient mortality. JAMA, 290(12), 1617-1623. https://doi.org/ 10.1001/jama.290.12.1617

Aylward, S., Stolee, P., Keat, N., \& Johncox, V. (2003). Effectiveness of continuing education in long-term care: a literature review. The Gerontologist, 43(2), 259-271. https://doi.org/10.1093/geront/43.2.259

Berthenet, M., Vaillancourt, R., \& Pouliot, A. (2016). Evaluation, modification, and validation of pictograms depicting medication instructions in the elderly. Journal of Health Communication, 21(sup1), 27-33. https://doi.org/10.1080/10810730.2015.1133737 
Billups, S. J., Malone, D. C., \& Carter, B. L. (2000). The relationship between drug therapy noncompliance and patient characteristics, health-related quality of life, and health care costs. Pharmacotherapy: The Journal of Human Pharmacology and Drug Therapy, 20(8), 941-949. https://doi.org/10.1592/phco.20.11.941.35266

Borg, C., Hallberg, I. R., \& Blomqvist, K. (2006). Life satisfaction among older people (65+) with reduced selfcare capacity: the relationship to social, health and financial aspects. Journal of Clinical Nursing, 15(5), 607-618. https://doi.org/10.1111/j.1365-2702.2006.01375.x

Burton-Jeangros, C., \& Zimmermann-Sloutskis, D. (2016). Life satisfaction trajectories of elderly women living in Switzerland: An age-period-cohort analysis. Ageing \& Society, 36, $106-132$. https://doi.org/10.1017/S0144686X14001044

C. D. Howe Institute. (2013). Long-Term Care for the Elderly: Challenges and Policy Option; Commentary, 367.

Canadian Institute for Health. (2018). Regulated Nurses, 2017: Data Tables. Retrieved on September 15th, 2018, from https:/www.cihi.ca/en/access-data reports/results?f\%5B0\%5D=field_primary_theme $\% 3 \mathrm{~A} 2047$

Canadian National Survey of the Work and Health of Nurses (NSWHN). (2005). Retrieved in November 22,2011 from http://www23.statcan.gc.ca/imdb/p2SV.pl?Function=getSurvey\&SDDS=5080\&Item_Id=13648

Canadian Nurses Association \& Registered Nurses' Association of Ontario. (2010). Nurse fatigue and patient safety: Research report. Ottawa, ON: CNA \& RNAO. Retrieved from http://www2.cnaaiic.ca/cna/practice/safety/full_report_e/files/fatigue_safety_2010_report_e.pdf

Canadian Nurses Association. (2013). Registered Nurses Role in Long-term Care. Retrieved from https://www.arnnl.ca

Canadian Nurses Association. (2015). Framework for the practice of registered nurses in Canada. Retrieved from http://www.cna-aiic.ca/ /media/cna/page-content/pdf-en/framework-for-the-pracice-of-registered-nurses-incanada

Chambers, R., \& FRCCP. (1999). Potential for the Abuse of Medication for the Elderly in Residential and Nursing Homes in the UK. Journal of Elder Abuse \& Neglect, 10(1-2), 79-89. https://doi.org/10.1300/J084v10n01_06

Chan, M., Nicklason, F., \& Vial, J. H. (2001). Adverse drug events as a cause of hospital admission in the elderly. Internal Medicine Journal, 31(4), 199-205. https://doi.org/10.1046/j.1445-5994.2001.00044.x

Chiappelli, M., \& Berardi, S. (2000). Pattern of intervention and patients' satisfaction with Community Mental Health Service in Bologna. Epidemiology and Psychiatric Sciences, 9(4), $272-281$. https://doi.org/10.1017/S1121189X0000840X

Clark, E., Draper, J., \& Rogers, J. (2015). Illuminating the process: Enhancing the impact of continuing professional education on practice. Nurse Education Today, 35, 388-394. https://doi.org/10.1016/j.nedt.2014.10.014

Cleary, K., \& Howell, D. (2007). Prescription Medication Use and Health-Related Quality of Life in Rural Elderly. Physical \& Occupational Therapy In Geriatrics, 26(2), 63-81. https://doi.org/10.1080/J148v26n02_04

Craig, G. (1995). Problems in the delivery of medical care to the frail elderly in the community. Journal of Management in Medicine, 9(2), 30-33. https://doi.org/10.1108/02689239510086515

Donabedian, A. (1966). Evaluating the quality of medical care. Milbank Memorial Fund Quarterly, 44, $166-203$.

Feletti, G., Firman, D., \& Sanson-Fisher, R. (1986). Patient satisfaction with primary-care consultations. Journal of Behavioral Medicine, 9(4), 389-399. https://doi.org/10.1007/BF00845122

Forbes, D. (2001). Canadian community-dwelling young-old and old-old: Determinants of satisfaction with health care. Canadian Journal on Aging, 20(1), 113-126. https://doi.org/10.1017/S0714980800012162

Fumić, N., Marinović, M., \& Brajan, D. (2014). Continuous nursing education to improve the quality of health care. Acta Medica Croatica, 68(Suplement 1), 13-15.

Grocki, J. H., \& Huffman, K. K. (2007). Medication adherence among older adults. Journal of Evidence-Based Social Work, 4(1-2), 97-120. https://doi.org/10.1300/J394v04n01_07

Hartz, A. J., Krakauer, H., Kuhn, E. M., Young, M., Jacobsen, S. J., Gay, G., ... \& Rimm, A. A.(1989). Hospital characteristics and mortality rates. New England Journal of Medicine, 321(25), 1720-1725. https://doi.org/10.1056/NEJM198912213212506

Hayat, S., Khan, S., \& Sadia, R. (2016). Resilience, Wisdom, and Life Satisfaction in Elderly Living with Families 
and in Old-Age Homes. Pakistan Journal of Psychological Research, 31(2), 475-494.

Health Force Ontario Canada. (2015). Health Force Annual Report (2014/2015), Health Force Ontario Marketing and Recruitment Agency. Retrieved from http://www.healthforceontario.ca/UserFiles/file/Floating/Publications/hfomra-ar-14-15-en.pdf

Hsieh, C-H. (2009). Health, Quality of Care and Quality of Life: A Case of Frail Older Adults. Social Indicators Research, 94(1), 61-73. https://doi.org/10.1007/s11205-008-9336-2

Institute of Medicine (IOM). (1999). To Err Is Human: Building a Safer Health Care System. Washington, DC: National Academies Press.

Living in Canada. (2015). Average Salary in Canada - Average Canadian Salary (Canadian Salaries - Wages in Canada - Average Pay in Canada). Retrieved from https://www.livingin-canada.com/work-salaries-wages-canada.html

Lu, L., \& Chang, C. J. (1997). Social Support, Health and Satisfaction among the Elderly with Chronic Conditions in Taiwan. Journal of Health Psychology, 2(4), 471-80. https://doi.org/10.1177/135910539700200404

McCartan-Quinn, D., McAleer, E., \& Naqvi, I. (1996). Service quality: A satisfaction survey of the Elderly. International Journal of Health Care Quality Assurance, 9(3), 4-10. https://doi.org/10.1108/09526869610117720

Mehdi, Z. (2015). Further education and training of care workers and professional development, work situation and quality of patient care: a quantitative and comparative analysis of Germany and Canada. Doctoral Dissertation, University of Vechta, Germany.

Millard, P. (1989). Geriatric medicine beyond the hospital. Age and Ageing, 18, 1-3. https://doi.org/10.1093/ageing/18.1.1

Mollaoglu, M., Tuncay, F., \& Fertelli, T. (2010). Mobility disability and life satisfaction in elderly people. Archives of Gerontology and Geriatircs, 51, e115-e119. https://doi.org/10.1016/j.archger.2010.02.013

Muliira, J. K., \& Muliira, R. S. (2012). Nurses' Orientation towards Lifelong Learning: A case study of Uganda's national hospital. The Journal of Continuing Education in Nursing, 43(2), 90-92. https://doi.org/10.3928/00220124-20111003-03

Mwanri, L., \& Fuller, J. (2003). Falls in the elderly: challenges and opportunities in the rural settings: the Whyalla case. Preliminary report. Health Education, 103(5), 296-304. https://doi.org/10.1108/09654280310499073

National Pay Scale. (2015). Salary Data \& Career Research Center (Canada). Retrieved from https://www.payscale.com/research/CA/Country=Canada/Salary

Needleman, J., Buerhaus, P., Mattke, S., Stewart, M., \& Zelevinsky, K. (2002). Nurse staffing levels and the quality of care in hospitals. New England Journal of Medicine, 346(22), 1715-1722. https://doi.org/10.1056/NEJMsa012247

Perez, F., Fernandez, G., Rivera, E., \& Rojo Abuin, J. (2001). Ageing in Place: Predictors of the Residential Satisfaction of Elderly. Social Indicators Research, 54(2), 173-208. https://doi.org/10.1023/A:1010852607362

Silber, J. H., \& Rosenbaum, P. R. (1997). A spurious correlation between hospital mortality and complication rates: The importance of severity adjustment. Medical Care, 35, OS77-OS92.

Statistics Canada. (2010). Survey of Labour and Income Dynamics (SLID) - 2010. Statistics Canada's Research Data Centres.

Statistics Canada. (2017). Statistics Canada Census 2016: Share of seniors in Canada's population sees biggest increase since Confederation.

Stewart, M., J., Neufeld, A., Harrison, M. J., Spitzer, D.. Hughes, K , \& Makwarimba, E. (2006). Immigrant women family caregivers in Canada: implications for policies and programmes in health and social sectors. Health and Social Care in the Community, 14(4), 329-340. https://doi.org/10.1111/j.1365-2524.2006.00627.x

Stiggelbout, A. M., Van der Weijden, T., De Wit, M. P., Frosch, D., Légaré, F., Montori, V. M., ... Elwyn, G. (2012). Shared decision making: really putting patients at the center of healthcare. BMJ: British Medical Journal (Online), 344. https://doi.rog/10.1136/bmj.e256

Stone, R. I., \& Weiner, J. M. (2001). Who will care for us? Addressing the long-term care workforce crisis. 
Washington, DC: The Urban Institute.

Turcotte, M., \& Schellenberg, G. (2007). A portrait of seniors in Canada, 2006. Statistics Canada, Social and Aboriginal Statistics Division.

Urquhart, J. (1994). Role of patient compliance in clinical pharmacokinetics. Clinical Pharmacokinetics, 27(3), 202-215. https://doi.org/10.2165/00003088-199427030-00004

Walker, A. (2005). A European perspective on quality of life in old age. European Journal of Ageing, 2(1), 2-12. https://doi.org/10.1007/s10433-005-0500-0

Wilhelmson, K., Andersson, C., Waern, M., \& Alleberck, P. (2005). Elderly people's perspectives on quality of life. Ageing \& Society, 25(4), 585-600. https://doi.org/10.1017/S0144686X05003454

Woolf, A. D., \& Akesson, K. (2003). Preventing fractures in elderly people. BMJ: British Medical Journal, 327(7406), 89-95. https://doi.org/10.1136/bmj.327.7406.89

Zaninotto, P., Falaschetti, E., \& Sacker, A. (2009). Age trajectories of quality of life among older adults: Results from the English longitudinal study of ageing. Quality of Life Research, 18(10), 1301-1309. https://doi.org/10.1007/s11136-009-9543-6

\section{Copyrights}

Copyright for this article is retained by the author(s), with first publication rights granted to the journal.

This is an open-access article distributed under the terms and conditions of the Creative Commons Attribution license (http://creativecommons.org/licenses/by/4.0/). 